\title{
NON-LINEAR OPERATOR AND THE SUFFICIENT CONDITIONS OF UNIVALENCE WITH APPLICATIONS
}

\begin{abstract}
Adel A. AtTiya
Abstract. In the present paper, by using a nonlinear operator, we obtain a general theorem of univalence which refines and generalizes many results. Some applications of the main results are also considered.

Mathematics subject classification (2010): 30C55, 30C80.

Keywords and phrases: Analytic functions, univalent functions, Hadamard product, general Schwarz lemma, operators in geometric function theory.
\end{abstract}

\section{REFERENCES}

[1] J. W. AleXANDer, Functions which map the interior of the unit circle upon simple region, Annals of Math. 17 (1915), 12-22.

[2] A. BARICZ AND B. FRASIn, Univalence of integral operators involving Bessel functions, Appl. Math. Lett., 23 (4) (2010), 371-376.

[3] S. D. BernARDI, Convex and starlike univalent functions, Trans. Amer. Math. Soc. 135 (1969), 429449.

[4] N. N. PAScu, On a univalence criterion. II, in: Itinerant Seminar on Functional Equations, Approximation and Convexity (Cluj-Napoca, 1985), pp. 153-154, Preprint 86-6, Univ. Babes-Bolyai, Cluj-Napoca, 1985.

[5] D. Breaz And N. Breaz, Two integral operators, Studia Univ. Babeş-Bolyai Math. 47 (2002), no. $3,13-19$.

[6] N. Breaz, V. Pescar and D. Breaz, Univalence criteria for a new integral operator, Math. Comput. Modelling 52 (2010), no. 1-2, 241-246.

[7] B. C. CARLSON AND D. B. ShAFFER, Starlike and prestarlike hypergeometric functions, SIAM, J. Math. Anal. 15 (1984), no. 4, 737-745.

[8] R. J. Libera, Some classes of regular univalent functions, Proc. Amer. Math. Soc. 135 (1969), 429 449.

[9] S. S. Miller And P. T. Mocanu, Differential Subordinations: Theory and Applications, Series in Pure and Applied Mathematics, No. 225. Marcel Dekker, Inc., New York, 2000.

[10] G. I. ORos, G. ORos AND D. BREAZ, Sufficient conditions for univalence of an integral operator, J. Inequal. Appl. 2008 (2008), art. ID 127645, 1-7.

[11] V. PESCAR, Univalence of certain integral operators, Acta Univ. Apulensis Math. Inform. 12 (2006), $43-48$.

[12] V. PESCAR, On the univalence of an integral operator, Appl. Math. Lett. 23 (2010), no. 5, 615-619.

[13] V. Pescar And D. Breaz, Some integral operators and their univalence, Acta Univ. Apulensis Math. Inform. 15 (2008), 147-152.

[14] V. Ravichandran, Criteria for univalence of certain integral operators, Acta Univ. Apulensis Math. Inform. 17 (2009), 141-149.

[15] C. Selvaraj, K. R. KARThikeyan, Sufficient conditions for univalence of a general integral operator, Bull. Korean Math. Soc. 46 (2009), no. 2, 367-372.

[16] H. M. SRIVAstava And S. Owa, Current Topics in Analytic Function Theory, World Scientific Publishing Company, Singapore, New Jersey, London and Hong Kong, 1992. 